\title{
Análise dos benefícios ao SUS e seus usuários do diagnóstico precoce do câncer de colo de útero e câncer de mama: primeiros resultados
}

Glauce Araújo Taborda TEIXEIRA: Faculdade de Saúde Pública - FSP, Universidade de São Paulo - USP. ORCID: http://orcid.org/0000-0001-8593-5232

Brunna Verna Castro GONDINHO: Universidade Estadual do Piauí - UESPI. ORCID:

http://orcid.org/0000-0002-1061-4407

\section{Resumo}

Para o Brasil, a estimativa para cada ano do triênio 2020-2022 aponta que ocorrerão 625 mil casos novos de câncer, sendo que os tipos de câncer mais frequentes nas mulheres, exceto o câncer de pele não melanoma, são os cânceres de mama - 29,7\%, cólon e reto $9,2 \%$, colo do útero - 7,4\%, pulmão - 5,6\% e tireoide $-5,4 \%$. Nos países das Américas, o câncer é a segunda principal causa de morte. A Organização Pan-americana da Saúde destaca que quanto aos tipos de câncer com maior taxa de mortalidade, nas mulheres, são pulmão - 17,4\%, mama - 15,1\%, colorretal - 9,5\% e colo do útero - 5,2\%. De acordo com estudos, estimam-se que os custos totais do câncer no Brasil em 2017, considerando despesas do SUS e saúde suplementar, foram de $1 \%$ do PIB, R\$ 68,2 BI. O custo do tratamento do câncer de mama no estadio I corresponde a $20 \%$ quando comparado ao estadio III. Quanto ao colo do útero, a diferença se dá em 7\% com o tratamento por conização contra o valor do tratamento oncológico. À vista desses dados, a Organização Mundial da Saúde propõe medidas de ações estratégicas por meio de evidências clínicas a fim de estruturar o enfrentamento ao câncer. O Ministério da Saúde relata que dentre todos os tipos de câncer, os cânceres de mama e do colo do útero são os únicos em que se indica o rastreamento, ou seja, ações voltadas para identificação precoce do câncer mesmo sem sintomas. Para um diagnóstico precoce, a recomendação no Brasil pelo

Recebido: 5 out. 2020

Aceito: 21 out. 2020

Autor de correspondência: Glauce Araujo Taborda Teixeira

glauce.taborda@gmail.com

Conflito de interesses: As autoras declaram não haver nenhum interesse profissional ou pessoal que possa gerar conflito de interesses em relação a este manuscrito. Ministério da Saúde, é que a mamografia seja ofertada para mulheres entre 50 e 69 anos, a cada dois anos. A adoção dessa orientação ocorre, pois, a maior parte dos países que implantaram o rastreamento do câncer de mama teve impacto na redução da mortalidade por essa doença. $O$ câncer do colo do útero pode acometer mulheres que tiveram a primeira gestação antes dos 20 anos quando comparadas às mulheres que tiveram a primeira gravidez após os 25 anos, mas além deste fator de risco, há dentre outros: infecção pelo vírus do papiloma humano (HPV), histórico sexual, tabagismo e uso prolongado de pílulas anticoncepcionais. O presente estudo não tem a intenção de citar valores, partindo do pressuposto que cada paciente tem um custo a partir do diagnóstico e do estadio de cada doença, no entanto, faz-se necessária a exposição acima para efeito comparativo de valores gerais e custo médio por doente. Dessa maneira, espera-se com este estudo analisar os benefícios ao SUS e seus usuários quanto às políticas de saúde voltadas para os exames de rastreamento relacionando com o diagnóstico precoce nos casos de câncer de colo de útero e câncer de mama, a fim de fornecer evidências para tomadores de decisão ampliarem uma estratégia mais eficaz para maximizar a saúde da população. Objetivo: Realizar busca na literatura do que há sobre o impacto financeiro ao Sistema Único de Saúde do diagnóstico precoce para os casos de câncer de mama e câncer de colo de útero. Como objetivos específicos, este estudo pretende: a) Identificar ações em saúde que promovam os exames de rastreamento para diagnóstico precoce do câncer de colo de útero e de mama aos usuários SUS; e b) Analisar estudos que indiquem 
os gastos em saúde com medicina preventiva e tratamento curativo. Método: O estudo trata-se de uma revisão integrativa da literatura. A presente pesquisa parte do questionamento "Segundo a literatura científica, quais os benefícios ao SUS e seus usuários do diagnóstico precoce do câncer de colo de útero e câncer de mama com ênfase no impacto financeiro do SUS?". A busca ocorreu por meio eletrônico a partir de descritores (DECS) correlacionados com o acervo da Biblioteca Virtual da Saúde (BVS). Considera-se como contexto: o Sistema Único de Saúde; como fenômeno: o impacto financeiro do diagnóstico precoce e; como população: casos de câncer de mama e câncer de colo de útero. Considerações finais: A partir da técnica do funil, definida a estratégia para busca na Biblioteca Virtual da Saúde - BVS "(tw:(sistema unico de saude)) OR (tw:(saude publica)) AND (tw:(avaliacao em saude)) OR (tw:(financiamento da assistencia a saude)) OR (tw:(gastos em saude)) OR (tw:(diagnostico precoce)) OR (tw:(diagnostico precoce de cancer)) AND (tw:(neoplasias de mama)) OR (tw:(neoplasias do colo do utero)) OR (tw:(colo do utero)) OR (tw:(mama))"; a qual reportou 1167 publicações. Nestas publicações aplicado o critério de inclusão texto completo disponível, publicações dos últimos 5 anos e com os idiomas português, inglês e espanhol que reportou 184 publicações. A busca foi exportada para o programa COVIDENCE. Como não houve duplicata, foi feita análise de títulos e resumo, passando para 48 estudos para revisão de texto completo, evoluindo para 8 estudos extraídos, ou seja, este foi o número final que seguirá para abordagem no presente artigo. Para chegar a este número, na revisão de texto completo, foram considerados como fatores excludentes: estudos anteriores a 2016, já que o critério eram artigos com até 5 anos; estudos com a população errada, quando se tratam de artigos que restringem à análise da população local (não brasileira) e ainda quando não se trataram da população exclusivamente feminina em relação ao câncer de mama e/ou colo de útero; e estudos com a configuração errada, ou seja, a população está correta, é abordada a temática do câncer de colo de útero e/ou de mama, no entanto compara métodos de exames e não faz menção significativa ao incentivo nos exames de rastreamento.

Descritores: Detecção Precoce de Câncer; Financiamento da Assistência à Saúde; Sistema Único de Saúde; Colo do Útero; Mama.

Keywords: Early Detection of Cancer; Healthcare Financing; Unified Health System; Cervix Uteri; Breast.

Palabras-claves: Detección Precoz del Cáncer; Financiación de la Atención de la Salud; Sistema Único de Salud; Cuello del Útero; Mama. 